\title{
Integrating Innovations for Sustainable Development in Africa
}

\author{
James Jude *, Abubakar Kazeem, Emeka Joseph, Assim Valentina
}

Science Policy and Innovation Studies (SPIS) Department, National Centre for Technology Management (NACETEM), North Central Office, FMST, Nigeria

\begin{abstract}
The field of innovation has been extensively researched, but less work has been done on integrated approach to innovations targeted at actualization of the Sustainable Development Goals (SDGs). The goals are closely interconnected, changing one goal will result in a change in another and this has resulted on the need for holistic approach to achieving Sustainable Development (SD). No doubt there exist interrelations between the sectors and subsector addressed by the goals and targets equally. Studies have shown that sustainable development challenges require an integrated response. It is in fulfilment of the three-pillars of the SDGs and Agenda 2063 that this paper articulated a tailor-made Conceptual Integrated Innovations Model with emphasis on the role of collaborations for innovation with the view to fast-tracking the attainment of the former and latter. In the end, the Performance Indicators for an integrated innovation will be an Africa that speaks with one voice, open and aligned to eco-innovations.
\end{abstract}

Keywords : Integration, Innovation, Sustainable Development, Agenda 2063, Africa

\section{INTRODUCTION}

There is only a thin line between integration, ecoinnovation and sustainable development. Not because the literature have not made efforts to dichotomize these fields of study, but the trio are horizontal policy fields, sharing facets with each other [Nisida, 2011] and with other policy areas. The rate of increase of awareness among policymakers on the impact of innovative activities on economic progress and wellbeing as well as the environment may not be directly proportional to the global challenges in domains as environment and health however, such gaps can only be covered with inclusive innovations.The idea behind Sustainable Development Goals (SDGs) was premised on "Whole of Development" for member countries of the United Nations (UN) as its success depends on participation, communication and partnership. Emphasis is on the explicit interest of the normative direction of development, with the intent of the balanced tri-pillar approach (economic, environmental and social) for sustainability [Nisida, 2011]. In the past, innovation processes may have been effectively managed by individual firms, however this is no longer true. Successful innovation is increasingly seen as the result of team's effort amongst a collection of players. Innovation is now seen as an interactive process requiring intense traffic of facts, ideas and reputational information within and beyond the firm. It is even clearer that innovating firms 'cannot be analysed in isolation: innovation capability depends in fact also on the amount of information that each firm is able to receive from the environment in which it operates [Obinna, 2016].

The ideologies advanced by integrated innovations is at par with that of Total Innovations Management (TIM) (see Olamade et al., 2014). SDGs are not a list of 
targets, but are closely interconnected hence, changing one goal will result in a change on another and this has resulted on the need for integrated approaches to achieving sustainable development which will ensure optimal achievement of SDGs by taking into consideration the interrelations between the sectors and subsector addressed therein. For innovations to be synchronized, it must be managed as a whole. However, Bleischwitz et al. (2009) observed that the process of integration of sustainability into innovation is not an easy task, this is due to sectorial, specialization and "departmentalization". This encompasses the management of an innovative value network that dynamically integrates concept, strategy, technology, structure and business process, culture, and people at all levels of an organization or a nation [Olamade et al., 2014]. Apparently, the need to develop a vision that marries technological development, innovation, role of institutions, and social advancement opens up a box of challenges begging for solutions. The quest for greener, cleaner and more equitable economic growth to address the box of challenges opened by innovation issues, not only from economic perspective, but social and environmental [Bleischwitz et al. 2009]. The former also have policy and governance implications. Hence, the model of SDG, which is underpinned by socially, environmentally and economically sustainable innovations. The gap between Africa and the developed countries widens by the day. This gap can only be bridged with collaborative approaches to innovations.

Questions as: how much synergy aimed at attaining SDGs do African countries enjoy? What quantum of the SDGs were factored into the Africa 2063 agenda? Is there any African-like integrated-innovation model in place for adoption and/or adaption by UN member countries to drive SDGs in Africa?

The object of this paper is centered on developing an empirical integrative innovation-model suitable for adoption by UN member countries in Africa for
Sustainable Development. Efforts were made to articulate the role of collaborations for innovation in fast-tracking the attainment of SDGs in Africa. The third plank of this paper is to drive home the tacit impact of included innovations on SDGs.

\section{METHODS AND MATERIAL}

\subsection{The concept of Innovation}

Although the innovation concept is founded in the economics disciplines, its theoretical definition stretches across many other fields. New innovation concepts such as "eco-innovation", "social innovation", "open innovation", or institutional, governance and organizational innovation are increasingly regarded as a "window of opportunity" for the markets and society to move towards societal progress with equal, lowcarbon and knowledge economy. The context of ecoinnovation may determine how successfully the innovation is received and diffused, but finding opportunities for innovation first requires an understanding of where it comes from and which direction the innovation should take (increasing quality of products, improving ecological environment, diversifying products, etc.) [Nisida, 2011].

Innovation is perceived as a medium that could be the difference between the SDGs sinking or swimming in the future. For innovation to be truly impactful, it must be holistic. External factors/influence made Sustainable Development (SD) to support systemic innovative approach. Deploying same techniques for decades cannot deliver desired results as other external factors would have changed over time hence, Cornish, (2017) coined a mantra "Innovate or fail!" to buttress the significance of innovation in fulfilment of SDGs.

Innovation generates new and contextual solutions as well as ideas that are required to solve societal problems at scale with impacts. But, selling new ideas at corporate level is usually challenging, partly owing 
to paradigm paralysis or exclusively because new ideas lose attention, except it gains management support. Actually, Cornish (2017) supported Schwaab and Giersch (2011) in the latter's opinion that innovations may not swim unless it gains acceptability of stakeholders. Both writers opined that the effective management of stakeholder's engagement and sound environmental scanning are pertinent to the swimming or sinking of innovative ideas in the paradigm ocean. In the light of that, the conversion from idea to innovation is the responsibility of seasoned top management.

For the purpose of this paper, the authors see innovation system as a sustainable conglomeration of interactive organizations, institutions, government and decision making tools supported by funding mechanisms where innovative activities are shaped for soci-economic benefits.

\subsection{Innovation Types and Topology}

Innovation as a field and concept has been extensively reviewed by scholars. Prominent among the types offered are along dimensions as product, process or system. Based on the Schumpeter's typology, innovation could be subdivided into product ("new good") or process ("new method of production"). Innovation could also be termed as incremental or radical, depending on the newness of the service/product offered. Incremental innovation on one hand, is based on a new technology or process which is slightly different from its predecessor. On the other hand, an innovation is perceived to be radical in nature as soon as new technologies and/or processes which are significantly different from the predecessor are introduced [Bleischwitz et al. 2009]. Component (modular) innovations take place when one or more modules integrated within a larger system are replaced while the system itself remains intact. The antithesis of which is architectural (systemic) innovations which entails system design-out and hence the way the parts interact with each other. The features mentioned herein are shared commonly among various types of innovation, such as technological, institutional, organizational, open and social innovation [Rennings, 2000].

Organizational innovations are, for example, management instruments at the firm level, like ecoaudits, which are of increasing importance for innovation [Rennings, 2000]. Social innovations are often defined as changes of lifestyles and consumption patterns. The idea of social innovation is new, but increasing gaining popularity as policy makers recognize that effective environmental policy-making requires understanding of lifestyle dynamics [Duchin 1999]. Recent trends in R\&D by private firms are encouraging open innovation, which may instigate spillover within a national economy.

Enkel et al. (2009) has since viewed open innovation to include the outside-in, inside-out and coupled processes. The first, is a process where organizations of nations fast-track innovation by creating innovation networks to harness external knowledge. The second process occurs when companies or countries sought to externalize knowledge and innovative ideas in order to attract market faster and thus speeding the market innovation. The authors also observed that the coupled process is an amalgam of the former and the latter processes. Authors of this paper aligned coupled process of innovation to integrated innovations, since this method help industries and economies to jointly develop and commercialize innovation.

\subsection{Well-Performing Process and Components of Innovation}

Ideas make no impact unless they are translated to innovations. Apparatus such as formal network/community and Culture of creativity are two basic elements that result in innovation. Network could stimulate new project concepts as well as help 
experts reflect and improve on tools and techniques. Networks are most important platforms for knowledge sharing, innovation and learning. Usually, innovation emerges when boundaries between disciplines are crossed hence, it is largely supported by collaboration [Schwaab and Giersch, 2011]. In the same vein, the authors opined elements such as interesting challenges, a degree of freedom, ability and opportunity trigger new ideas and result in creativity. Secondly, when there is need to scale-up (replication/adaptation) of situation-specific ideas and when there is willingness and capacity to arrange the scaling up process [Schwaab and Giersch 2011].

Creativity flourish in an environment (trust, openness, networking, brainstorming and exchange of ideas, sharing methodologies, stakeholders' participation, clear orientation and rules, etc) that is open to idea. Innovations need time to grow, develop and become effective, hence innovators need to be patient [Schwaab and Giersch, 2011].

Although the literature acknowledges that it is not possible to specify an ideal innovation process, but a proposal could be advanced to nurture the shape of a well-performing processes like that offered by Nisida, (2011). In his proposal, items such as Knowledge and Economic Competence, Institutional Features, Technical Features, Regulatory Features, Networking Features and expected Outcomes were prerequisites for rating an innovative endeavor as a well preforming innovation process or otherwise.

An innovation system is more likely to be effective if it includes a diverse range of organizations or nations with different and high levels of economic competence. The system is likely to operate more effectively if it included firm and non-firm organizations, demanding customers, and new industry players. The performance of the system will also be optimized if individual players effectively manage their value-chains.
Another performance component of innovation is Institution. Little wonder, Karen (2003) tagged institutions as the 'rule of the game'. Nisida, (2011) opinion was hinged on the fact that innovation systems will perform better if there is a strong cultural emphasis on the importance of fairness and if local customs and routines reward innovativeness. However, in Joe (2006) review of innovation models, the author supported the views of Nisida, (2011) in articulating the fact that innovation systems performance is critically affected by the quality and accessibility to technical support infrastructure such as $\mathrm{R} \& \mathrm{D}$, training, education, finance and intellectual property arrangements and the need to be focused on innovation outcomes. Both authors strongly articulated training and breeding grounds to experiment ideas as technical features for a wellprocessed innovation system.

In addition, stringent regulatory features may subdue innovative ideas while scope for innovation is maximised if technical, safety, environmental and other regulation are expressed in terms of ultimate performance requirements, instead of tightly specified prescriptive requirements. Maximum advantage will be gained if external linkages are dense, multistranded, long-term, knowledge-intensive, vertical and horizontal, market and non-market oriented, and inclusive of innovation, production and distribution relationships. Trust and robust user-producer relationships will also ideally be evident. Such factors support the development of effective dynamics within innovation systems. Innovation system outcomes will be maximized if individual participants perceive benefits beyond what they could achieve in isolation. The system is then more likely to be stable and productive [Nisida, 2011].

\subsection{The role of Innovations in Sustainable Development}


Despite the problematic issues in defining the concept of innovation, some generalisations could be made concerning the nature of innovation towards SD. Hence, innovations for SD is dynamic since the challenges in innovation do not rest solely on economic benefits and opportunities, but also on the societal changes induced by innovative capacity and the consequences therein. The eco-innovations that are most likely to succeed in pushing the economy towards sustainable development had been postulated to be those that include the social and institutional dimensions [Nisida, 2011].

Thus, sustainable technology is not producing products and services without pollution or ecological destruction but fulfilling the needs of mankind in manner that the recovery capability of the earth as well as the recovery capacity of local ecosystems are not exceeded. The purpose is to ensure that the earth's use of natural resources is within the limits set by its recovery capacity. The following are the preconditions advanced for innovations to be SD compliant.

Fulfillment of needs - Analyzing the need that is fulfilled by the product is the first step to developing technologies for sustainable development. These needs may be consumer, organisational or governmental needs. The issue however is to develop more sustainable alternatives to fulfil the identified needs. To open minds for alternative ideas, it is important that brainstorm sessions are organized to generate alternative modes of need fulfillment. If adequate brainstorming is carried out, many alternatives will be obtained from different sectors. However the precondition for coming up with these alternatives is to focus on fulfilling a need and on improving existing technology.
Thinking globally - Just following needs in a very efficient way does not always result in sustainable solutions. And technologies that are very environmentally efficient might have various negative side effects or have longer-terms effects or might only be applicable on a small scale. Hence, innovation for sustainable development requires a holistic view of innovation. There is need to act locally, but there is more need to evaluate technologies globally and with longterm view.

Looking for long-term solutions - Little improvements in environmental efficiency are good but are not adequate as the purpose is making leaps. Improving existing technology is less risky compared to targeting breakthrough technology. Though market concept creates a short-term mindset in organisations and stakeholders. However, it advised that approaches to innovation for sustainable development should support long-term thinking.

\subsection{Technology and Sustainable Development}

The world's population is estimated to be at least 9 billion by 2050 hence, the need to innovate for sustainable development. By implication to keep the environmental burden at the level it is today, environmental efficiency of technology, should improve considerably as affluence of nations especially developing countries will improve considerably. There are a lot of factors that contribute to the reduction of environmental burdens of human activities. It should be noted that successful introduction of new technologies always result in sociotechnical solution. Technology has been classified according to the levels of effect they have on current technological systems [Mulder, 2007]. See table 1 below: 
Table 1 : Classification of Technology

\begin{tabular}{|c|c|c|c|c|c|c|}
\hline $\mathrm{S} / \mathrm{N}$ & $\begin{array}{l}\text { Technology } \\
\text { Type }\end{array}$ & Function & $\begin{array}{l}\text { Resource } \\
\text { predominantly } \\
\text { used }\end{array}$ & $\begin{array}{l}\text { Resource } \\
\text { efficiency }\end{array}$ & $\begin{array}{l}\text { Emissi } \\
\text { ons }\end{array}$ & $\begin{array}{l}\text { Impact on natural } \\
\text { systems }\end{array}$ \\
\hline 1 & $\begin{array}{l}\text { Preindustrial } \\
\text { technologies }\end{array}$ & To provide & Renewable & Low to high & Low & $\begin{array}{l}\text { Some over exploitation } \\
\text { often compensated by } \\
\text { low density } \\
\text { population }\end{array}$ \\
\hline 2 & $\begin{array}{l}\text { Classical } \\
\text { environmental } \\
\text { technologies }\end{array}$ & $\begin{array}{l}\text { To prevent } \\
\text { harm by } \\
\text { pollution }\end{array}$ & Nonrenewable & Low & High & $\begin{array}{l}\text { Ecological destruction } \\
\text { outside settlement }\end{array}$ \\
\hline 3 & $\begin{array}{l}\text { Good } \\
\text { housekeeping } \\
\text { technologies }\end{array}$ & $\begin{array}{l}\text { To mitigate } \\
\text { pollution }\end{array}$ & Nonrenewable & $\begin{array}{l}\text { Medium to } \\
\text { low }\end{array}$ & $\begin{array}{l}\text { Mediu } \\
\mathrm{m} \text { to } \\
\text { low }\end{array}$ & $\begin{array}{l}\text { Mitigation of ecological } \\
\text { destruction }\end{array}$ \\
\hline 4 & $\begin{array}{l}\text { End-of-pipe } \\
\text { technologies }\end{array}$ & $\begin{array}{l}\text { To prevent } \\
\text { pollution } \\
\text { after process }\end{array}$ & Nonrenewable & $\begin{array}{l}\text { Medium to } \\
\text { low }\end{array}$ & Low & $\begin{array}{l}\text { Less pollution, at the } \\
\text { expense of extra } \\
\text { resources use }\end{array}$ \\
\hline 5 & $\begin{array}{l}\text { Process } \\
\text { adaptation/da } \\
\text { mage } \\
\text { prevention }\end{array}$ & $\begin{array}{l}\text { To prevent } \\
\text { pollution } \\
\text { arising from } \\
\text { process }\end{array}$ & $\begin{array}{l}\text { Nonrenewable } \\
\text { and renewable }\end{array}$ & High & Low & $\begin{array}{l}\text { Less pollution and less } \\
\text { resources use }\end{array}$ \\
\hline 6 & $\begin{array}{l}\text { Sustainable } \\
\text { technologies }\end{array}$ & $\begin{array}{l}\text { To provide } \\
\text { within the } \\
\text { limits of the } \\
\text { earth's } \\
\text { carrying } \\
\text { capacity }\end{array}$ & Renewable & High & None & $\begin{array}{l}\text { Balance between } \\
\text { humanity and the } \\
\text { natural environment }\end{array}$ \\
\hline
\end{tabular}

Source: (Karel F. Mulder, 2007)

As against the conventional technologies must be developed for sustainability. Environmental technologies are concerned with production of good and services with minimal pollution while sustainable technologies ensures the needs of the whole of humanity are fulfilled without:

i. Exhausting the earth's nonrenewable resources

ii. Exceeding its ecological recovery capacity

iii. Consolidating or promoting inequality
2.6 Whole-of-Government and Whole-ofInnovation for SDGs

SDGs are at the heart of the 2030 Agenda for Sustainable Development and are closely interconnected. Changing one goal will result in a change on another and this has resulted on the need for integrated/interconnected policy making. Integrated policies and Whole-of-Government (WoG) approaches help governments and organizations to ensure sustainable development more effectively, by 
taking into consideration the interrelations between economic, social and environmental dimensions as well as between the sectors and subsectors addressed by the goals and targets.

Most countries struggle to deliver integrated, interconnected and cross-sectorial services due to sectorial specialization or "departmentalization". This often results in partial solutions that are inadequate from a broader sustainable development point of view [Berger and Steurer, 2009].

Sustainable development challenges require a holistic and integrated response. Development in the socioeconomic and environmental areas should not be pursued as competing agendas to be "traded-off". Policy interventions designed to have impact on one area can ultimately have far reaching and wider consequences than those initially intended, including on other areas (Berger and Steurer, 2009). The need to deal with the integrative challenges of sustainable development becomes even more visible when dealing with a host of closely interlinked policy domains.

Policy integration entails taking into account interlinkages among different areas of policy. Integration here implies that policymaking in any one area takes into account the effects of (and on) policies and outcomes in other sectors and areas. Such a holistic approach helps ensure that policies are coherent across the full range of sustainable development dimensions, E-government has an important role to play in policy integration for each dimension and across all of the three dimensions of sustainable development and between different sectors or subsectors [UNEP 2009].

\section{The Millennium Development Goals (MDGs)} succeeded in demonstrating the power of shared goals. The SDGs are far broader, integrating the economic, social and environmental agendas across all geographies and applying both to developed and developing economies. The SDGs apply to all of us with no exceptions, and provide a universally agreed definition of "a better future". The 17 SDGs, with 169 associated targets, represent a breath-taking level of ambition in both the scale and scope of change, with timelines for achievement in 2030 or earlier. Successful delivery of the SDGs requires major changes to the way different economies and their underlying sectors work together globally, as well as the speed at which innovative ideas and best practice are propagated around the world at all levels. Governments, sectors, and individual organizations are beginning to formally recognize the SDGs and have aligned their developmental plans to the SDGs [Deloitte, 2016].

\section{INTEGRATED INNOVATION}

The post-2015 Development Agenda and SDGs are viewed as a global, national and local social contract that hinged on communication, participation and partnership. A seamless network comprising multistakeholder, multi-dimension approaches and collaboration is required at all levels to ensure effective planning and implementation. There is no better way to actualize the Agenda and Goals than by taking advantage of the innovation that could be explored from the linkages among the global, national and local areas for the effectiveness of the social contract. The SDGs are not simply a list but a deep web of inter-relationships where progress towards one goal could enhance progress to another goal. Hence achieving the SDGs requires a systemic and integrated approach such that a goal is being worked on with possible enhancement in other goals in mind. The first step in SDGs is adapting it to national levels and this will require a lot of partnerships through several formats.

Integration of the environment into development planning is vital for sustainable development. Also, it is opined that a fundamental reshaping of decisionmaking as well as significant changes in the institutional structure of government are important to 
ensure more systematic consideration of the environment across sectors in policy.

Some opportunities that exist for integration includes creating real linkages with local level planning and decision-making and forging partnership with the media to advance communication and awareness as partnership and communication are keywords for the social contract.

One issue to consider for effective integration of innovations is proper stakeholders engagement and this is because of the scope of the SDGs which support the concept of 'everything' and 'everyone'. Other issues to consider are massive data requirements and analysis needed to track progress and the customization of indicators as well as incorporation in a results-based management framework for countries who have already started to integrating SDGs into national development plans. Some capacity gaps that need to be bridged for MDG-SDG transition are mainstreaming of SDGs, integrated systems tools, recognition of alignment of SDGs with existing agencies amongst others.

Sector-based development strategies are inadequate hence the need for holistic (system-wide) approach to sustainable development. Also important is the need for a more coherent and integrated planning and decision making at the national, state and local levels [UNEP, 2009].

To arrest the complex challenges of actualizing sustainable development from 'leadership and guidance' perspective a new multilateral governance architecture: High Level Political Forum (HLPF) on sustainable development was created and the Forum noted the intrinsic inter-linkage between poverty eradication and the promotion of sustainable development and highlighted the need for a coherent approach that integrates in a balanced fashion the three dimension of sustainable development: economic, social \& environmental.

One of the key tasks of the Forum is to study and follow-up on sustainable development commitments and objectives in an integrated and holistic manner as well as conduct national appraisal of implementation progress of both developed and developing member states.

Substantial progress has be made among many member countries in developing and adopting national SD strategies and plans which integrate environmental, social and economic dimensions and recognizes their interlinkages. Despite this progress, it has been identified that such plans and strategies lack integration, inclusion and coherence as countries main focus continues to be on economic growth, poverty reduction, etc leaving behind the integration of environmental considerations.

Literature over the last few decades have shown inadequacy of sectorial and silo-based planning approaches to address complex global and national SD challenges whose interdependencies and interlinkages transcend individual sectors and national boundaries. Traditional sector-based approaches and tools are not adequate for this purpose as the challenges are more complex and systemic in nature. Thus the Integrated Systems Approach (ISA) is key to SD planning and formulation. Government across the globe are now faced with designing and implementing strategies, plans and policies that target holistic transformation and stabilization which requires acknowledgement and adequate understanding of the dynamic interdependence and interconnectedness of numerous complex systems and sub-systems such as water, energy and ecosystems as well as their impact and changes they will undergo from different future threats including climate change.

It is believed that for transformative actions to be achieved, top-level political leaders involvement is 
crucial for getting overall pull across a country and that national visions are important tools.

\subsection{Integrated Innovation Model}

Figure 1 identified and represented the four major levels of innovation as; the local, national, continental and global. Figure 2 is a representation of integrated innovative activities occurring at every level of the Innovation Cone. For instance, each circle in the larger circles of each level encapsulated by the cone is represented by the exploded view in Figure 2. In figure 1 , the framework assumed that an integration of all innovative activities at province levels sum up to that obtainable at the national level. In the same vein, continental innovative activities conglomerate to global indicators. But, the framework holds flow of information, knowledge and sustainability to the core of the innovation cone. The adoption of the shape was hinged on the seamless nature of the cone. Information, knowledge and support for sustainability should be borderless and smooth especially in Africa.

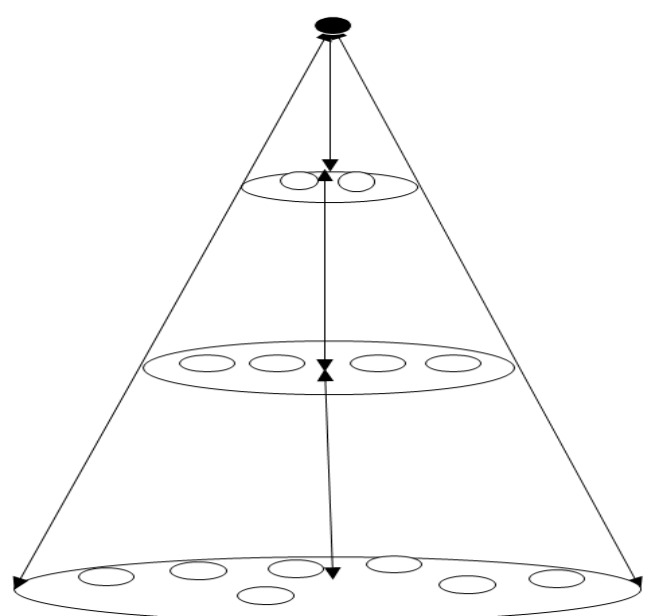

Figure 1 : Conceptual Model for Integrated Innovations for Sustainable Development

The traditional model characterizes innovation as a linear sequence running from basic research, through product development, to production and marketing [Godin, 2005]. Innovation is now seen as an interactive process requiring intense traffic in facts, ideas, knowledge, policy frameworks and reputational information within and beyond organizations and nations particularly for the SDGs which are interconnected [Karen, 2003]. The author also identified 16 Interactive Innovation Frameworks with emphasis on four (4) key approaches: systems, networks, value-chains and clusters. The researchers made an attempt to develop an integrated innovation model using the result of the comparative analysis of the four key approaches.

This paper argued that understanding the links between the actors as knowledge flows, institutions, economic competence and interactive learning in innovation processes is the key to improving innovative performance. Other relevant elements of innovation are network, partnership, communication and participation.

Knowledge flow is a parameter used in measuring the knowledge distribution power of an interactive innovation system. The major strength of the NIS lies in the ability of the structure to track the linkages among interacting elements as the Government, Industry, Academia and Fund (GIAF) in the development of technological and organizational innovations.

The governance of movement has since been viewed as the functions of institutions. This Karen, referred to as the 'rules of the game'. This movement facilitates learning and innovation.

An innovation system can be defined as a collection of 'organizations, institutions, government and people that interact in the production and diffusion of new economically useful knowledge [Lundvall, 1992]. Innovations are not only developed but also produced, diffused, and used. They also change during these processes. For any nation, success relies on relationships with external parties. This view is 
supported by numerous empirical studies. The multiphase interactions amongst the academia, government and industries allows exchange of knowledge, R\&D and innovations. The link further strengthens the integration or adaptation of developmental plans to national plans, hence promoting the actualization of SDGs.

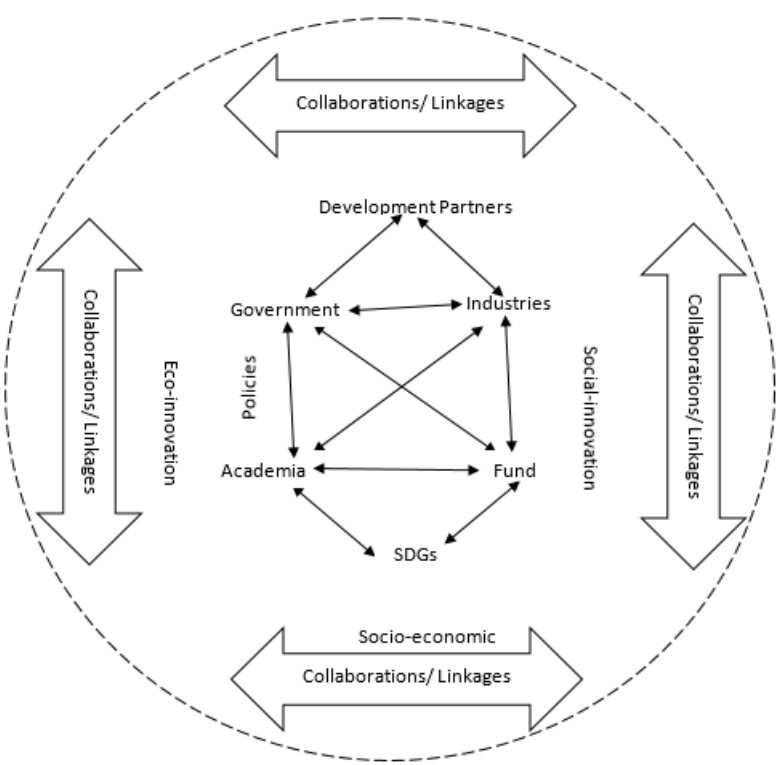

Figure 2 : Explicit Conceptual Model for Integrated Innovations for Sustainable Development

The vertical and horizontal linkages existing along the boundaries of the open-end system in Figure 2 is a demonstration of the implications of relevant interactions within and outside provinces in the UN members countries and globe. These collaborations serves as idea generating hubs, information and technology sharing platforms and stimulants of innovations. We argued also that for an innovation system to be integrated, elements as funding should be the concern of the government, academia as well as the industries. The latter provides sink capital ventures as succor to the risks of innovators. In the same vein, such fund should be monitored and evaluated by the stakeholders, government, and authorities with monitoring and evaluation mandate against the parameter that must gain the support of the academia while providing the breeding ground for innovators, hence Karen viewed institutions as the "rule of the game".

The value-chain [Karen, 2003] of knowledge offered by the academia towards the attainment of the SDGs expectantly gains financial support from both government and development partners. The ecoinnovation, social-innovation and socioeconomic features of the model epitomize the three pillars of SDGs. Contrary to the linear model of innovation that postulated innovation to commence with basic research, then applied $R \& D$, and ends with production and diffusion, the Integrated Innovations for Sustainable Development (IISD) model strongly proposed that basic research may not be crucial to integrated innovations since Africa is not expected to reinvent the wheels. Synergy, research output and findings from universities and research institutes are expected to be synchronized to impact on industrial, commercial and administrative processes of the continent.

In Africa, Government, being the major sponsor of research must make deliberate and conscious effort to exploit key motivational factors as part of strategic planning for boosting and sustaining quality research [Yusuf, 2012] outputs specifically, targeted at SDGs. This the African Union (AU) may champion by promulgating policies targeted at SDGs attainment. It is important to keep options open by maintaining a broad array of innovation interests through multiple relationships. This model supported the opinion of Rothwell's fifth generation model of innovation [Joe, 2006] that promoted the integration and extensive networking, flexible and customized response and continuous innovation, with specific adaptations. In many respects Karen's (2003) model emphasized relationships with diverse players and networking/learning in particular institutional contexts. The researcher concluded on linkages with external parties, organization with economic competence and outcomes as three key indicators for 
measuring the level of interactions of an innovation system.

The proposed integrated innovation model saw a gap in aforementioned models. First, both models are silent about environmental impacts of innovative activities. Much emphasis was placed on synergy, but no attention was given to funding of researches and sustainability of the innovation systems. The open ended nature of the circumference in the proposed model portrays continuity and sustainability of innovation process. Sustainable development requires a long-term transformation/innovations, planning processes than the usual annual budgets or mediumterm expenditure frameworks. This model argued that the sustainability of funding mechanisms, environmentally friendly policies and greeninnovations are tasks huge enough for the government to collaborate on. More so, the proposed 15-year strategies the SDGs will require planning over a period of several decades, hence this model finds application even beyond the attainment of the SDGs.

In addition, the ideas of "everything and everyone" upheld by the SDGs were enshrined in the agenda 2063. The 50-year plan was factored into the IISD model. It builds on, and sought to accelerate the implementation of past and existing continental initiatives for growth and sustainable development.

\section{CONCLUSION}

The post-2015 Development Agenda and SDGs were viewed as a global, national and local social contracts hinged on communication, participation, collaborations and partnerships. SDGs are not a list of targets, but a closely interconnected programmes that support integration and innovations.

Innovation is perceived as a medium that could be the difference between the SDGs sinking or swimming in the future. This paper postulated the need for a change in the modus operandi of SDGs, claiming the deployment of the same techniques for decades cannot deliver desired results since other external factors would have changed between one developmental goal and another. The foregoing was to buttress the significance of innovation in fulfilment of SDGs.

There is need for a coherent approach that integrates in a balanced fashion the three dimension of sustainable development: economy, social and environment. A handful of efforts and progress might have been made at developing and adopting national SD strategies, regrettably, some of such strategies lack integration, inclusion and coherence.

Africa has to speak and work with one voice, with Big Picture in mind always. Africans must think and act holistically rather than individually. The continent must align with global trends. It is crystal clear that collaborative efforts are better fast tracked when all the elements in National Innovation Systems are integrated. That is what innovation is and when it makes better impacts.

This paper proposed a conceptual integrative innovation-model that is adoptable by UN member countries in Africa for Sustainable Development. It articulated the role of collaborative innovation in fasttracking the attainment of SDGs in Africa as well as show the need for included innovations on SDGs.

The IISD model accentuated relationships with diverse players and networking/learning in particular institutional contexts. The conceptual integrative innovation model was developed using the result of the comparative analysis of the four relevant models. The authors stressed the need to understand the link among actors as knowledge flows, institutions, economic competence and interactive learning are pertinent in an innovation chain. This proposed link further strengthens the integration of developmental plans with national plans while promoting the actualization of SDGs. 
The proposed model highlighted the linkage among interacting keys elements as the Government, Industry, Academia and Fund (GIAF) to innovations. This multi-phase interactions allow exchange of knowledge, R\&D and innovations.

\section{REFERENCES}

[1]. [E-GOVERNMENT IN SUPPORT OF SUSTAINABLE DEVELOPMENT, UNITED NATIONS E-GOVERNMENT SURVEY 2016], Department of Economic and Social Affaris, United Nations, New York, 2016, publicadministartion.un.org

[2]. [WORLD POPULATION 2015] Wallchart. [online]

https://esa.un.org/unpd/wpp/publications/Files/ WPP2015_Volume-I_Comprehensive-

Tables.pdf. [Accessed: 25th April, 2017]

[3]. https://www.devex.com/news/innovation-inhumanitarian-response-a-must-have-withdisclaimers- 90161 [ Accessed: 3rd May, 2017]

[4]. J. A. Schwaab and M. Giersche, [INTEGRATED INNOVATION MANAGEMENT FOR SUSTAINABLE DEVELOPMENT, WHEN KNOWLEDGE MEETS CREATIVITY], Sustainable Mountain Development No. 58, ICIMOD, Spring 2011

[5]. K. F. Mulder, [INNOVATION FOR SUSTAINABLE DEVELOPMENT: FROM ENVIRONMENTAL DESIGN TO TRANSITION MANAGEMENT], Integrated Research System for Sustainability Science and Springer, Vol. 2, p. 253 - 263, 2007.

[6]. http://www.un.org/disabilities/documents/rio20 _outcome_document_complete.pdf [Accesed May 5, 2017]

[7]. https://www.un.org/pga/wpcontent/uploads/sites/3/2015/08/120815_outco me-document-of-Summit- for-adoption-of-the- post-2015-development-agenda.pdf [Accessed May 5 2017]

[8]. http://www.un.org/en/africa/osaa/pdf/au/agend a2063.pdf [Accessed May 5 2017]

[9]. UN-DESA, [DIVISION FOR SUSTAINABLE DEVELOPMENT], [Report of the Capacity Building Workshop and Expert Group Meeting on Integration Approaches to Sustainable Development Planning and Implementation] United Nations, 2015.

[10]. Obinna, O. O. \& Simon, D.T.R (2016) [BEFORE SUSTAINABLE DEVELOPMENT GOALS (SDG): WHY NIGERIA FAILED TO ACHIEVE THE MILLENNIUM DEVELOPMENT GOALS (MDGS)]. Pan African Medical Journal; 24:156. Available online at: http://www.panafricanmed-journal.com/content/article/24/156/full/

[11]. Karen, M. (2003) [FRAMEWORKS FOR UNDERSTANDING INTERACTIVE INNOVATION PROCESSES]. International Journal of Entrepreneurship and Innovation, 4(1), pp. 25-36.

[12]. Deloitte, LLP, [MOBILE INDUSTRY IMPACT REPORT: SUSTAINABLE DEVELOPMENT GOALS]

[13]. AUC [AFRICAN AGENDA 2063, THE AFRICA WE WANT]. Presented By: Directorate of Strategic Policy Planning, 2016

[14]. Nisida, G. (2011). [INNOVATION AND SUSTAINABLE DEVELOPMENT: LINKAGES AND PERSPECTIVES FOR POLICIES IN EUROPE.] ESDN Quarterly Report June 2011

[15]. Yusuf, A. K. (2012). [AN APPRAISAL OF RESEARCH IN NIGERIA'S UNIVERSITY SECTOR] JORIND 10 (2), June, 2012. ISSN 1596 - $\quad 8308 . \quad$ www.transcampus.org./journals, www.ajol.info/journals/jorind

[16]. Bleischwitz R., Giljum S., Kuhndt M., SchmidtBleek F. (2009): [ECO-INNOVATION: PUTTING THE EU ON THE PATH TO A RESOURCE AND ENERGY EFFICIENT 
ECONOMY]. Wuppertal Special 38. Wuppertal:

Wuppertal Institute

[17]. Duchin, F., [REDUCING PRESSURES ON THE ENVIRONMENT: FORWARD-LOOKING SOLUTIONS AND THE ROLE OF FORMAL MODELS. THEORETICAL APPROACHES AND EMPIRICAL ANALYSIS]. Physica Verlag, Heidelberg, New York.1999.

[18]. Enkel,E., Gassmann, O. and Chesbourg, H.: [OPEN R\&D AND OPEN INNOVATION: EXPLORING THE PHENOMENON] R\&D Management 39 (4): 311-315, 2009.

[19]. Huber, J. THE LOST INNOCENCE OF ECOLOGY: NEW TECHNOLOGIES AND SUPER-INDUSTRALIZED DEVELOPMENT. Frankfurt am Main: Fischer Verlag, 982, 1982.

[20]. Joe, T . [A REVIEW OF INNOVATION MODELS] Discussion Paper 1. Science and Technology Policy Research Unit. University of Sussex. Imperial College London 2006.

[21]. Godin, B. [THE LINEAR MODEL OF INNOVATION: THE HISTORICAL CONSTRUCTION OF AN ANALYTICAL FRAMEWORK. PROJECT ON THE HISTORY AND SOCIOLOGY OF S\&T STATISTICS] Working Paper No. 30, 2005.

Cite this article as :

James Jude, Abubakar Kazeem, Emeka Joseph, Assim Valentina, " Integrating Innovations for Sustainable Development in Africa, International Journal of Scientific Research in Science and Technology(IJSRST), Print ISSN : 2395-6011, Online ISSN : 2395-602X, Volume 6, Issue 1, pp.166-178, January-February-2019. Available at doi : https://doi.org/10.32628/IJSRST19617 Journal URL : http://ijsrst.com/IJSRST19617 